\title{
A randomized, double-blind, comparative study for efficacy assessment of two hyaluronic acid nasolabial fillers
}

\author{
Saman Ahmad Nasrollahi ${ }^{1,2}$, Mansour Nassiri Kashani ${ }^{1}$, Taraneh Yazdanparast $^{1}$, Setareh Ameri ${ }^{1}$, \\ Alireza Firooz ${ }^{1,2^{*}}$ \\ ${ }^{1}$ Pharmaceutical, Cosmeceutical and Hygienic Products Clinical Evaluation Lab (DermaLab), Center for Research \& Training in Skin Diseases \& Leprosy,
Tehran University of Medical Sciences, Tehran, Iran \\ ${ }^{2}$ Cosmetic Products Research Center, Food and Drug Organization, MOH \& ME, Tehran, Iran
}

\begin{abstract}
Hyaluronic acid fillers are considered safe for use in cosmetics as described in the safety assessment. This study was aimed to assess and compare the efficacy and safety of two hyaluronic acid (HA) fillers on mild nasolabial folds. Ten women aged 30-50 years with mild nasolabial folds participated for injection of A and B gels into right or left nasolabial folds. The volume and surface of nasolabial folds were measured by CSI software and the density and thickness of dermis assessed by skin ultrasonography before and 2, 12, and 24 weeks after injection. The data were analyzed using SPSS software version 20 , and $p$-value $<0.05$ were considered as significant. Global assessment showed over $50 \%$ improvement in patients injected with both gel A and B. At 2 weeks after injecting gel A the volume and surface of wrinkles decreased significantly. In the side injected with gel B, this reduction was significant at 2 and 12 weeks after injection. In addition, 24 weeks after injection of both gels the dermis echo-density increased and the dermis thickness decreased. This study indicated the significant positive filling effect of both HA fillers in decreasing the clinical signs of wrinkles at nasolabial folds. Comparing both fillers, there were not any statistically significant differences in any of measurements, but the persistence of gel B to improve the wrinkle appearance was slightly better than gel A.
\end{abstract}

Keywords: hyaluronic acid; filler; ultrasonography

Citation: Nasrollahi SA, Kashani MN, Yazdanparast T, Ameri S, Firooz A. A randomized, double-blind, comparative study for efficacy assessment of two hyaluronic acid nasolabial fillers. J Surg Dermatol 2022; 7(1): 170; http://dx.doi. org/10.18282/jsd.v7.i1.170.

*Correspondence to: Alireza Firooz, Dermatologist, Professor of Center for Research \& Training in Skin Diseases \& Leprosy, Tehran University of Medical Sciences (TUMS), \# 415 Taleqani Ave, Tehran, Iran; alifiruz@yahoo.com

Received: $1^{\text {st }}$ September 2021; Accepted: $16^{\text {th }}$ October 2021; Published Online: $3^{\text {rd }}$ November 2021

\section{Introduction}

Skin aging includes a flattening of the epidermal-dermal interface and some breakdown of the dermal tissue; this layer is a protective and nutritive tissue with main components of collagen, elastin and hyaluronic acid to provide flexibility and elasticity of the skin and protects skin against dehydration ${ }^{[1,2]}$. The majority of age-dependent changes happen in the dermis and include breakdown of collagen and elastin, reduction in skin thickness, loss of hyaluronic acid and consequently skin volume and dehydration in the dermis which extrinsically lead to create wrinkles ${ }^{[1-3]}$. Hyaluronic acid is the most important glycosaminoglycan (GAG) which causes skin elasticity and has the unique capacity to contain water and make the skin hydrated. In addition it has a role in cell growth and function of membrane receptors, also leads to stability of cellular structures and creates a viscoelastic network for collagen and elastin fibers to connect to each other; these benefits make hyaluronic acid as excellent dermal filler ${ }^{[4,5]}$.

One of the signs of aging is vertical lines on either side

Copyright (C) 2022 Nasrollahi SA, et al. This is an Open Access article distributed under the terms of the Creative Commons Attribution-NonCommercial 4.0 International License (http://creativecommons.org/licenses/by-nc/4.0/), permitting all non-commercial use, distribution, and reproduction in any medium, provided the original work is properly cited. 
of the mouth which is called nasolabial folds or laugh line. Injectable fillers in treatment for facial rejuvenation have become an increasingly prevalent feature to grow the population wanting to reverse the aging process. Through recent advances in injection techniques, newer types of dermal fillers have been approved, providing practitioners the option of administering soft tissue fillers such as cross linked hyaluronic acids with minimal inconvenience to the patient ${ }^{[6,7]}$. This study was designed to assess and compare the efficacy and safety of two soft tissue fillers on mild nasolabial folds using non-invasive measurement techniques.

\section{Materials and methods}

\section{Study design and injection technique}

This randomized clinical trial was performed in the Pharmaceutical, Cosmeceutical and Hygienic Evaluation Lab (DermaLab) of Center for Research \& Training in Skin Diseases \& Leprosy, Tehran University of Medical Sciences (TUMS) from May 2013 to April 2014. After signing the written informed consent and according to the Wrinkle Severity Rating Scale, 10 women aged 30-50 years with mild nasolabial folds and and skin type III-IV were recruited. The exclusion criteria were a recent history of any skin disease or operation in the previous 3 months, any systemic disease that can affect skin status, pregnancy, any other previous cosmetic intervention on the nasolabial fold such as HA, collagen and fat injection, laser therapy, peeling, or non-ablative rejuvenation procedures in the year prior to start day of the study and a history of smoking.

Participants received $1 \mathrm{ml}$ of gel A (Hyamax Deep Line manufactured by Laboratories Hyamed, Switzerland) randomly on one of nasolabial folds and gel B (Yvoire Classic S manufactured by LG Life Sciences, South Korea) was injected in the opposite side. Both fillers contained $22 \mathrm{mg} / \mathrm{ml} \mathrm{HA}$ and all injections were done with standard technique for dermal fillers.

The subjects were uninformed about the gel types and instructed not to use any pharmaceutical, cosmeceutical or hygienic products on their skin on the night prior to the injection. To anaesthetize the region, a thin layer of Janucaine cream (containing lidocaine $2 \%$ and prilocaine $2 \%$, Janus pharmaceutical company, Iran) was applied to both nasolabial folds and occluded for 30 minutes.

\section{Assessment}

All assessments were done prior to the treatment and 2, 12 and 24 weeks after injections (follow up visits). A frontview digital photo of the face was taken for comparing before-after photos by two independent dermatologists according to the Physician Global Assessment (PGA) five-point scale: 1- Worse: exacerbation, 2- No change: improvement of $24 \%$ or less, 3- Fair: improvement of 25 49\%, 4- Good: improvement of 50-74\%, 5- Excellent: improvement of $75 \%$ or more ${ }^{[8]}$.

High-resolution images of the nasolabial fold were taken by VisioFace (CK electronic GmbH, Cologne, Germany) then the volume and surface of wrinkles were measured by the related Complete Skin Investigation (CSI) software. The change in volume and surface of wrinkles at each time point after injection were calculated as:

Value after injection - value before injection / value before injection

Furthermore $22 \mathrm{MHz}$ skin ultrasonography (DUB Skin Scanner, tpm, Luneburg, Germany) of nasolabial folds dermis were done at baseline and final visit (24 weeks after injection) to measure the dermis echo-density and thickness ${ }^{[9]}$. The subject's satisfaction of treatment was assessed by Visual Analogue Scale (VAS) ${ }^{[10]}$ on a $0-10$ scale which 0 is dissatisfied and 10 is extremely satisfied. Finally any possible adverse effects were asked and recorded on the 1-3 scale (1: mild, 2: moderate, 3 : severe).

\section{Statistical analysis}

The obtained data were entered in SPSS software version 20 and then mean score of parameters before and after intervention was analyzed by the paired T-test and p-value $<0.05$ was considered significant.

\section{Ethics}

The study was conducted in accordance with the ethical principles provided by Good Clinical Practice (GCP) and the Declaration of Helsinki and all volunteers provided written informed consent.

\section{Results}

All volunteers completed study period and there was no deviation from protocol. Regarding the safety, one participant reported mild bruising and the other one reported swelling, pain and mild stiffness at injection sites of gel A, which cleared spontaneously in a few days.

As depicted in figure 1, the volume and surface of wrinkles at 2, 12 and 24 weeks after injecting gel A decreased compared to baseline, which was statistically significant only 2 weeks after injection $(-45.94 \pm 20.74 \%$, pvalue $=0.000$ for volume of wrinkles and $-45.02 \pm 20.43 \%$, $\mathrm{p}$-value $=0.001$ for surface of wrinkles). In the side injected with gel $\mathrm{B}$; this reduction in wrinkles objective parameters was significant at week $2(-39.67 \pm 21.51 \%$, p value $=0.003$ for volume of wrinkles and $-39.56 \pm 17.16 \%$, $\mathrm{p}$-value $=0.001$ for surface of wrinkles) and week 12 $(-31.6 \pm 31.37 \%, p-$ value $=0.019$ for volume of wrinkles and $-34.68 \pm 23.59 \%, \mathrm{p}-$ value $=0.004$ for surface of wrinkles); 24 weeks after injection gel $\mathrm{B}$, just the reduction in surface of wrinkles was significant $(-22.23 \pm 23.14 \%$, $\mathrm{p}-$ value $=0.037)$.

In addition, 24 weeks after injection of gel A the echodensity of dermis increased significantly $(119.32 \pm 164.8 \%$, $\mathrm{p}$-value $=0.028$ ), and there was a non-significant decrease 
in the dermis thickness. The same changes occurred after injecting gel $\mathrm{B}$, significant increase in dermis density $(78.00 \pm 97.06 \%, \mathrm{p}$-value $=0.036)$, and non-significant decrease in the dermis thickness (Tables 1). Comparing both fillers, there were not any statistically significant differences in any of measurements.

The results of PGA considered the grade of correction of nasolabial folds and stability of both gels at 2, 12 and 24 weeks after injection (Table 2). This improvement was good or excellent (over 50\% improvement) in 8,6 , and 6 of 10 patients injected with gel A, and in 9,7 and 7 of 10 patients injected with gel B after 2, 12, and 24 weeks, respectively (Figure 2 and Table 2 ). The mean of PGA scores were not significantly different between two gels.

The mean patient satisfaction score at 2, 12 and 24 weeks after injection of gel A were $6.25 \pm 1.75,7.88 \pm$ 2.02 and $7.6 \pm 1.89$, respectively. 2,12 and 24 weeks after injecting of gel $\mathrm{B}$, these records were $7.4 \pm 1.34,7.44 \pm 1.66$ and $7.5 \pm 1.95$, respectively $(\mathrm{p}<0.05)$.

\section{Discussion}

In the past decade there has been a major shift in facial rejuvenation toward less invasive and even nonsurgical procedures with less downtime and less pain ${ }^{[11]}$. It is understandable that increased popularity of soft-tissue fillers is due to the effective results of restoring lost volume and correcting contour deficiencies to the aging face ${ }^{[12]}$. Due to the fact that aging is a continuous process, temporary fillers should be preferred over permanent ones ${ }^{[13]}$. Hyaluronic acid (HA)-based gels are now the gold standard and most commonly used dermal fillers in the US ${ }^{[14]}$.

In this before-after trial, the volume and surface of wrinkles in nasolabial folds have been reduced both objectively and subjectively 2, 12, and 24 weeks after injection of two HA fillers (Figure 1). These results can be due to the restoration of volume using dermal fillers which can rebalance facial proportion, increase symmetry and by reducing wrinkles, produce a younger appearance ${ }^{[11]}$.

The obtained results have been confirmed by physician assessments (Table 2), in accordance with biometric assays. In addition there was not any statistically significant difference between these two products, and both of them were able to reduce the symptoms of wrinkles.

The increased echo density of dermis can be due to the presence of hyaluronic acid composition in mentioned area. Furthermore, HA in the dermis can stimulate collagen synthesis; the cumulative effect of hyaluronic acid and collagen lead to the increase in the dermis density to mentioned rate (Table 1$)^{[15]}$. In contrast, both gels reduced the dermis thickness at the injection area due to the pressure effect of fillers on dermis which is the main role of fillers to treat the wrinkles. This finding has been reported previously ${ }^{[16]}$. The participant's satisfaction after injecting both fillers was considerable and no significant side effects

Table 1. The change in the echo-density and thickness of dermis 2, 12 and 24 weeks after injecting gel A in comparison with gel B.

\begin{tabular}{|c|c|c|c|c|c|}
\hline \multirow[t]{2}{*}{ Variable } & $\begin{array}{c}\text { The } \% \text { of } \\
\text { change of gel A } \\
\text { after } 24 \text { weeks }\end{array}$ & $\begin{array}{c}P \text {-value } \\
\text { (before-after } \\
\text { comparison) }\end{array}$ & $\begin{array}{c}\text { The } \% \text { of } \\
\text { change of gel B } \\
\text { after } 24 \text { weeks }\end{array}$ & $\begin{array}{c}P \text {-value } \\
\text { (before-after } \\
\text { comparison) }\end{array}$ & $\begin{array}{c}P \text {-value } \\
\text { (before-after } \\
\text { comparison) }\end{array}$ \\
\hline & Mean \pm SD $^{*}$ & & Mean \pm SD & & \\
\hline Dermis density & $\begin{array}{c}119.32 \% \\
164.80 \pm \\
\end{array}$ & 0.028 & $78 \% \pm 97.06$ & 0.036 & 0.178 \\
\hline Dermis thickness & $\begin{array}{c}-10.90 \% \\
\pm 19.61 \\
\end{array}$ & 0.081 & $\begin{array}{l}-8.35 \% \\
\pm 16.26 \\
\end{array}$ & 0.127 & 0.697 \\
\hline
\end{tabular}

Table 2. The physician global assessment of correction level and stability of gels A and B 2, 12 and 24 weeks after injection

\begin{tabular}{|c|c|c|c|c|c|c|}
\hline & \multicolumn{2}{|c|}{$\begin{array}{l}\text { week } 2 \\
(n=10)\end{array}$} & \multicolumn{2}{|c|}{$\begin{array}{l}\text { week } 12 \\
(n=10)\end{array}$} & \multicolumn{2}{|c|}{$\begin{array}{r}\text { week } 24 \\
(n=10)\end{array}$} \\
\hline & Gel A & Gel B & Gel A & $\begin{array}{c}\text { Gel } \\
\text { B }\end{array}$ & Gel A & Gel B \\
\hline 1- Worse: exacerbation & - & - & - & - & - & - \\
\hline 2- No change: improvement of $24 \%$ or less & - & - & 1 & 1 & 1 & 1 \\
\hline 3- Fair: improvement of $25-49 \%$ & 2 & 1 & 3 & 2 & 3 & 2 \\
\hline 4- Good: improvement of 50-74\% & 7 & 8 & 5 & 6 & 6 & 6 \\
\hline 5- Excellent: improvement of $75 \%$ or more & 1 & 1 & 1 & 1 & - & 1 \\
\hline The mean of PGA & 3.9 & 4 & 3.7 & 3.9 & 3.5 & 3.7 \\
\hline
\end{tabular}


$\mathbf{A}$

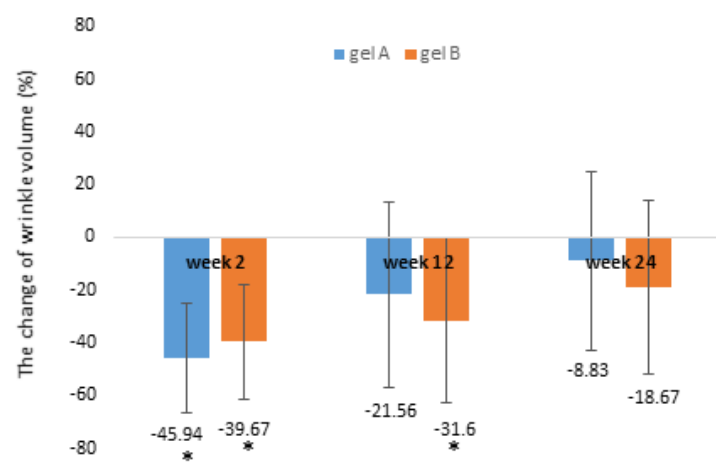

B

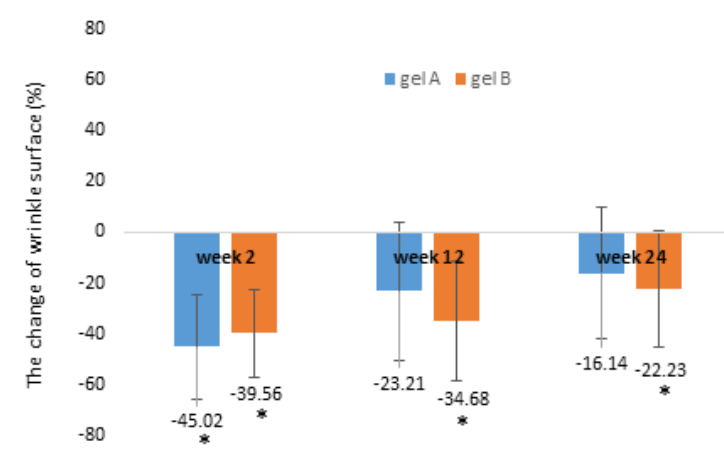

Figure 1. The change in the A) volume and B) surface of nasolabial folds 2, 12 and 24 weeks after injecting gel A in comparison with gel B. *: considered as significant percent of the change $(\mathrm{p}$-value $<0.05)$
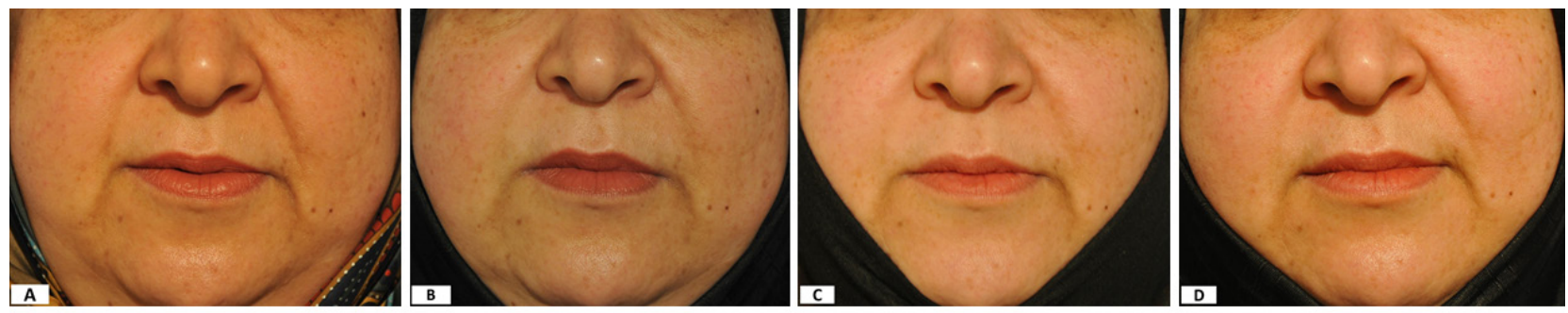

Figure 2. The photographs of nasolabial folds of a representative participant at baseline (A), 2 weeks (B), 12 weeks (C) and 24 weeks (D) after injection A and B gels. The nasolabial folds were treated on contralateral sides of the face with gel A in the participant right side and gel $B$ in left

were reported after injection. Bruising at the injection site was infrequent and disappeared spontaneously in a few days.

Our obtained results indicate no statistically significant difference between two HA fillers but a little better results of gel B in reducing wrinkle volume and surface compared to gel A can be due to different manufacturing processes with major influence on the characteristics of the biopharmaceutical final product, so even minor manufacturing processing differences may impact biological activity, safety and effectiveness of finished product $^{[17]}$.

\section{Conclusion}

In conclusion due to the differences between before and after injection and lack of major side effects in both gels, they can be safe and effective products to remove the wrinkles at nasolabial area. Totally because of the superior beauty results of HA fillers, they are still the best dermal aesthetic device to increase the volume of soft tissue. On the other hand they are absorbed and therefore cannot be a permanent solution to remove wrinkles.

\section{Acknowledgement}

The authors appreciate from Pariz Medical Equipment Co. and Omid Salamat Co., for financial support in present study.

\section{References}

1. Stern R, Maibach HI. Hyaluronan in skin: aspects of aging and its pharmacologic modulation. Clin Dermatol 2008; 26(2): 106-122. doi: 10.1016/j.clindermatol.2007.09.013.

2. Fisher GJ, Varani J, Voorhees JJ. Looking older: Fibroblast collapse and therapeutic implications. Arch Dermatol 2008; 144(5): 666-672. doi: 10.1001/archderm.144.5.666.

3. Bailey AJ. Molecular mechanisms of ageing in connective tissues. Mech Ageing Dev 2001; 122(7): 735-755. doi: 10.1016/S0047-6374(01)00225-1.

4. Masson F. Skin hydration and hyaluronic acid. Ann Dermatol Venereol 2010; 137(Suppl 1): S23-25. doi: 10.1016/S01519638(10)70005-3.

5. Lupo MP. Hyaluronic acid fillers in facial rejuvenation. Semin Cutan Med Surg. 2006; 25: 122-126. doi: 10.1016/ j.sder.2006.06.011.

6. Walter RJ, Matsuda T, Reyes HM, Walter JM, Hanumadass M. Characterization of acellular dermal matrices (ADMs) prepared by two different methods. Burns 1998; 24(2): 104113. doi: 10.1016/S0305-4179(97)00110-1.

7. Ascher B, Cerceau M, Baspeyras M, Rossi B. Soft tissue 
filling with hyaluronic acid. Ann Chir Plast Esthet 2004; 49(5): 465-685. doi: 10.1016/j.anplas.2004.09.001.

8. Choi YJ, Lee JY, Ahn JY, Kim MN, Park MY. The safety and efficacy of a combined diode laser and bipolar radiofrequency compared with combined infrared light and bipolar radiofrequency for skin rejuvenation. Indian $\mathrm{J}$ Dermatol Venereol Leprol 2012; 78(2): 146-152. doi: 10.4103/0378-6323.93630.

9. Dreno B, Araviiskaia E, Berardesca E, Bieber T, Hawk $\mathrm{J}$, Sanchez-Viera M, et al. The science of dermocosmetics and its role in dermatology. J Eur Acad Dermatol Venereol 2014; 28(11): 1409-1417. doi: 10.1111/jdv.12497.

10. Reips UD, Funke F. Interval level measurement with visual analogue scales in Internet-based research: VAS Generator. Behav Res Methods 2008; 40(3): 699-704. doi: 10.3758/BRM.40.3.699.

11. Monstrey SJ, Pitaru S, Hamdi M, Van Landuyt K, Blondeel $\mathrm{P}$, Shiri J, et al. A two-stage phase I trial of Evolence30 collagen for soft-tissue contour correction. Plast Reconstr Surg 2007; 120(1): 303311. doi: 10.1097/01. prs.0000264402.97692.b6.

12. Narins RS, Baumann L, Brandt FS, Fagien S, Glazer S, Lowe $\mathrm{NJ}$, et al. A randomized study of the efficacy and safety of injectable poly L-lactic acid versus human-based collagen implant in the treatment of nasolabial fold wrinkles. J
Am Acad Dermatol 2010; 62(3): 448-462. doi: 10.1016/ j.jaad.2009.07.040.

13. Sales AG, Lotierzo PH, Gimenez R, Camargo CP, Ferreira MC. Evaluation of poly-L-lactic acid implant for treatment of the nasolabial fold: 3-year follow-up evaluation. Aesthetic Plast. Surg 2008; 32(5): 753-756. doi: 10.1007/s00266-0089182-2.

14. Baumann LS, Shamban AT, Lupo MP, Monheit GD, Thomas JA, Murphy DK, et al. Comparison of smooth-gel hyaluronic acid dermal fillers with cross-linked bovine collagen: a multicenter, double-masked, randomized, within-subject study. Dermatol Surg 2007; 33(2): S128-35. doi: 10.1097/00042728200712001-00004.

15. Croce MA, Dyne K, Boraldi F, Quaglino D Jr, Cetta G, Tiozzo $\mathrm{R}$, et al. Hyaluronan affects protein and collagen synthesis by in vitro human skin fibroblasts. Tissue \& Cell 2001; 33(4): 326-331. doi: 10.1054/tice.2001.0180.

16. Kim J. Effects of Injection Depth and Volume of Stabilized Hyaluronic Acid in Human Dermis on Skin Texture, Hydration, and Thickness. Arch Aesthetic Plast Surg 2014; 20(2): 97-103. doi: 10.14730/aaps.2014.20.2.97.

17. Dranitsaris G, Dorward K, Hatzimichael E, Amir E. Clinical trial design in biosimilar drug development. Invest New Drugs 2013; 31(2): 479-487. doi: 10.1007/s10637-012-9899-2. 